OPEN ACCESS

Edited by:

Mara Biasin,

University of Milan,

Italy

Reviewed by: Karen Ingrid Tasca, São Paulo State University,

Brazil

Claudio Fenizia, University of Milan,

Italy

*Correspondence:

Chunyuan Zhao

cyzhao@sdu.edu.cn

Wei Zhao

wzhao@sdu.edu.cn

Specialty section:

This article was submitted to

Viral Immunology,

a section of the journal

Frontiers in Immunology

Received: 26 November 2020

Accepted: 24 March 2021

Published: 12 April 2021

Citation:

Zhang J, Zhao C and Zhao W (2021)

Virus Caused Imbalance

of Type I IFN Responses and Inflammation in COVID-19.

Front. Immunol. 12:633769. doi: 10.3389/fimmu.2021.633769

\section{Virus Caused Imbalance of Type I IFN Responses and Inflammation in COVID-19}

\author{
Jintao Zhang ${ }^{1,2}$, Chunyuan Zhao ${ }^{1,2,3 *}$ and Wei Zhao ${ }^{1,2 *}$ \\ ${ }^{1}$ Department of Immunology, School of Basic Medical Science, Cheeloo College of Medicine, Shandong University, \\ Jinan, China, ${ }^{2}$ State Key Laboratory of Microbial Technology, Shandong University, Jinan, China, ${ }^{3}$ Department of \\ Cell Biology, School of Basic Medical Science, Cheeloo College of Medicine, Shandong University, Jinan, China
}

The global expansion of coronavirus disease 2019 (COVID-19) caused by severe acute respiratory syndrome coronavirus 2 (SARS-CoV-2) has emerged as one of the greatest public health challenges and imposes a great threat to human health. Innate immunity plays vital roles in eliminating viruses through initiating type I interferons (IFNs)-dependent antiviral responses and inducing inflammation. Therefore, optimal activation of innate immunity and balanced type I IFN responses and inflammation are beneficial for efficient elimination of invading viruses. However, SARS-CoV-2 manipulates the host's innate immune system by multiple mechanisms, leading to aberrant type I IFN responses and excessive inflammation. In this review, we will emphasize the recent advances in the understanding of the crosstalk between host innate immunity and SARS-CoV-2 to explain the imbalance between inflammation and type I IFN responses caused by viral infection, and explore potential therapeutic targets for COVID-19.

Keywords: COVID-19, SARS-CoV-2, type I interferons, inflammation, innate immunity

\section{INTRODUCTION}

The global expansion of coronavirus disease 2019 (COVID-19) caused by severe acute respiratory syndrome coronavirus 2 (SARS-CoV-2) has emerged as one of the greatest public health challenges and imposes a considerable threat to human health. Similar to SARS-CoV and MERS-CoV infection, SARS-CoV-2 infection frequently induces high levels of proinflammatory cytokines, leukocyte changes, high D-dimer, and increased lactate dehydrogenase levels (1-3). COVID-19 exhibits varied clinical manifestations, ranging from fever, cough, diarrhea, and fatigue to pulmonary edema, septic shock, multiple organ failure, and even death. The multiple symptoms indicate that COVID-19 is a systemic inflammatory disorder rather than a single respiratory disease (2).

Innate immunity functions as the first line of defense for the host to eliminate invading viruses through the initiation of type I IFNs (including IFN- $\alpha$ and IFN- $\beta$ )-dependent antiviral responses and induction of inflammation (4). As a bridge, it initiates antiviral adaptive immune responses and controls the intensity of adaptive immunity. Therefore, optimal activation of innate immunity and balanced type I IFN responses and inflammation are beneficial for efficient elimination of invading viruses. However, excessive inflammation caused by viral invasion can induce excessive production of inflammatory cytokines and initiate acute respiratory distress syndrome (ARDS), which is associated with the increased 
risk of death $(1,5-7)$. In contrast to heightened levels of inflammation, reduced or delayed type I IFN responses accompanied by relatively high viral titers have been observed in COVID-19 patients, particularly in critical patients in intensive care units (ICU) $(8,9)$. While each cell population of patients with mild COVID-19 displays a coordinated interferon signature, those with severe cases are thought to dampen IFN responses through CD32b (10). Recent evidence from two translational medical researches similarly highlighted the importance of type I IFN. They confirmed that defective IFN signaling stands as the main causes of serious COVID-19 besides advanced age and underlying diseases and may account for nearly $13 \%$ of severe cases $(11,12)$. Imbalance between inflammation and IFN I responses indicates poorer prognosis for COVID-19 patients, and worse disease outcomes. In this review, we will emphasize recent advances in understanding the crosstalk between host innate immunity and SARS-CoV-2, and explain the imbalance between inflammation and IFN I responses to explore potential therapeutic targets for COVID-19.

\section{ENTRY OF SARS-COV-2}

Like many other respiratory coronaviruses, SARS-CoV-2 mainly infects the host via the respiratory tract and is transmitted via respiratory droplets (13) (Figure 1). The SARS-CoV-2 genome is approximately $29.7 \mathrm{~kb}$ long and encodes four structural proteins (spike protein $\mathrm{S}$, envelope protein $\mathrm{E}$, membrane protein $\mathrm{M}$, and nucleocapsid protein N), 16 non-structural proteins (NSPs), and 9 accessory proteins (14-16), which share high sequence similarity to their SARS-CoV counterparts.
Among all the viral proteins, the $S$ protein initiates the infection process by mediating the attachment of the virus to host cells through angiotensin-converting enzyme 2 (ACE2) (13). ACE2 mainly exists in the intestine, heart, kidneys, and testes, and it is correlated with the distribution of SARS-CoV-2 (17). According to single-cell RNA sequencing (scRNA-Seq), the expression of ACE2 in the lungs was primarily observed in the alveolar type II cells (AT2), which are probably the primary target of SARS-CoV-2 (18). The latest longitudinal study in conjunction with airway and blood samples also indicates that severe inflammation during SARS-CoV-2 infection is mainly driven by cytokines in the lung rather than systemic (19). Even worse, the SARS-CoV-2-induced IFN I responses also evidently increase the cellular ACE2 levels, which may increase susceptibility to infection (20). In addition, SARS-CoV-2encoded $\mathrm{N}$ protein, NSP7b, and NSP8 all participate in viral replication, evolution, and immune evasion during infection (21, 22). Emerging evidence confirms that both structural and nonstructural proteins of SARS-CoV-2 interfere with host innate immune responses and participate in the pathogenesis of COVID-19 (14, 23).

\section{INNATE IMMUNE RESPONSES AGAINST SARS-COV-2}

To effectively defend against viruses, host cells initiate antiviral innate immune responses by producing a number of IFNs and other proinflammatory cytokines. IFNs and downstream interferon-stimulated genes (ISGs) play fundamental roles in

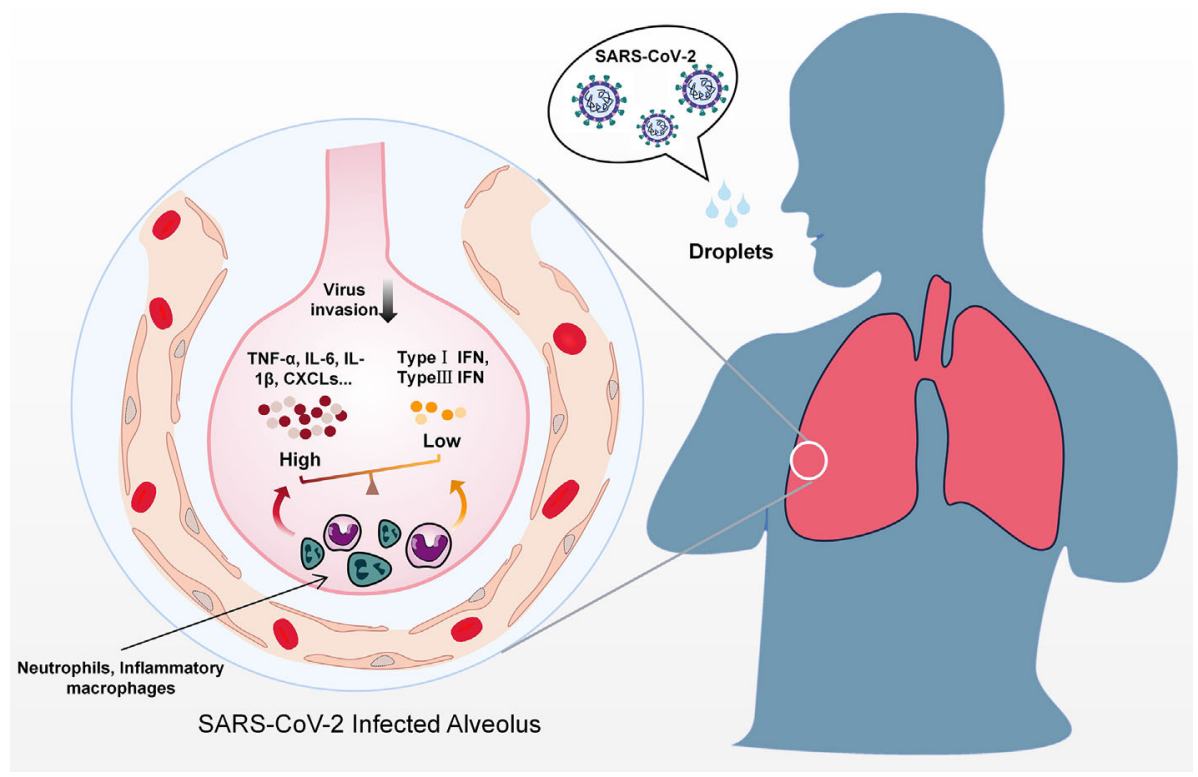

FIGURE 1 | Predicted immune dysregulation in the lung during SARS-CoV-2 infection. After contact with droplets containing SARS-CoV-2, host immune responses are activated in the lung. Activation of immune cell subgroups such as inflammatory macrophages and neutrophils results in the secretion of massive amounts of inflammatory cytokines, including TNF- $\alpha$, IL-6, IL-8, and CXCLs. In contrast to excessive proinflammatory cytokines, IFNs levels are lower during the early phase of infection. 
limiting viral replication (24) (Figure 2). Following invasion, SARS-CoV-2 releases viral RNA and proteins into cells, which are recognized by the host immune system as pathogen associated molecular patterns (PAMPs), thus initiating the secretion of IFNs and antiviral innate immune responses (25). Various pattern recognition receptors (PRRs), including Tolllike receptor 3 (TLR3), TLR7, TLR8, retinoic acid-inducible gene I (RIG-I), and melanoma differentiation-associated protein 5 (MDA5) are candidates for the recognition of SARS-CoV-2, since they are considered to sense viral components; particularly viral RNA (26). Among these PRRs, RIG-I/MDA5 are proven to be the main sensors in MERS-CoV recognition and inflammatory cascade initiation (27). TLR7/8 is also reportedly involved in sensing coronaviruses including SARS-CoV (28).

PRR signaling activated by viral components induces nuclear factor (NF) $-\mathrm{KB}$ activation, which triggers the expression of a large number of proinflammatory cytokines. Some of the metabolites as oxidized phospholipid (OxPL) are also increased during coronavirus infection, further triggering NF-kB activation via TLR4 (29). NF- $\kappa B$ activation induces the expression of nucleotide-binding oligomerization domain-, leucine-rich repeat- and pyrin domain-containing 3 (NLRP3), pro-IL-1 $\beta$, and pro-IL-18 (the priming stage of the NLRP3 inflammasome). Subsequently, cellular damage or distress caused by viral infection, leading to the accumulation of reactive oxygen species and ion fluxes (damage associated molecular patterns, DAMPs), results in the activation stage of NLRP3 inflammasome (30). NLRP3 inflammasome activation then mediates the maturation of IL-1 $\beta$, IL-18, and the propyroptotic factor gasdermin D (GSDMD), and thus induces inflammation-associated cell death known as "pyroptosis" and further amplifies host inflammatory responses (30, 31) (Figure 2).

The activation of multiple PRRs facilitates the establishment of antiviral states by recruiting multiple adaptor proteins (e.g., mitochondrial antiviral signaling protein (MAVS), TANK binding kinase 1 (TBK1), tumor necrosis factor receptorassociated factor (TRAF) 3 and TRAF6) and inducing a variety of cytokines. On this basis, different immune cells are recruited to infection sites and initiate adaptive immune responses (32). Although substantial IFN I responses and optimal inflammation are beneficial for the eradication of invading viruses, an imbalance between type I IFN responses and inflammation induced by different viral proteins can cause numerous detrimental effects (Figure 1). In a SARS-CoV-2 infection hamster model, significant inflammation occurred in distal tissues even while productive SARS-CoV-2 replication was low (33). In the late phase of infection, a large increase in delayed type I IFN responses occurs, which induces the secretion of proinflammatory cytokines such as $\mathrm{C}-\mathrm{X}-\mathrm{C}$ motif chemokine

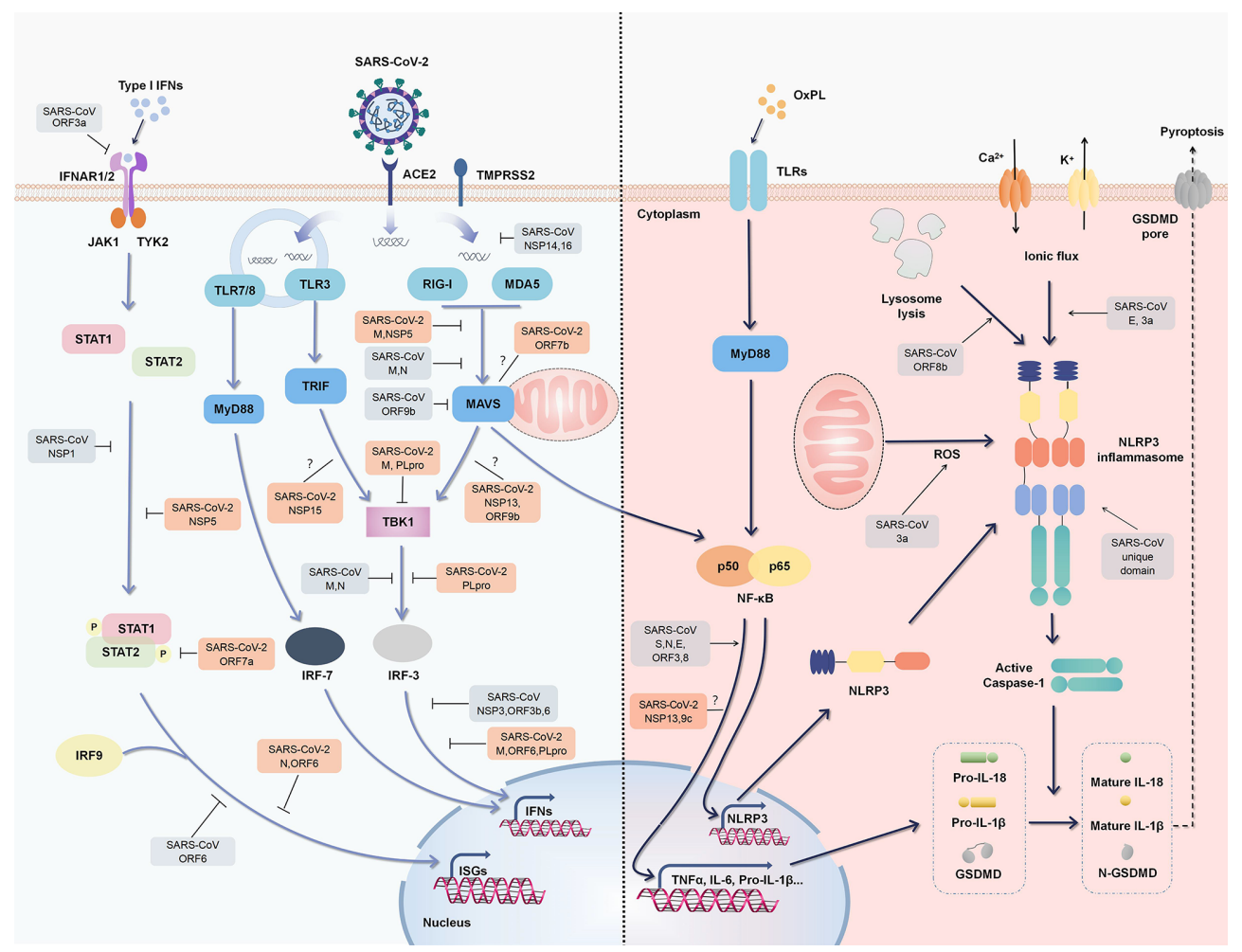

FIGURE 2 | Regulation of type I IFN responses and inflammation by SARS-CoV-2 and SARS-CoV. An outline of IFN signaling (left) and major inflammatory signaling (right) is shown, annotated with the known mechanisms by which SARS-CoV activates or suppresses signals (gray). Some SARS-CoV-2 proteins have also been confirmed or speculated to interact with these pathways (orange). 
ligand 10 (CXCL10) found in pulmonary autopsy tissues, and recruits and activates inflammatory monocyte-macrophages, resulting in the impairment of $\mathrm{T}$ cell responses and lung immunopathology $(34,35)$. A similar situation was also revealed when single-cell RNA-seq was performed using peripheral blood mononuclear cells obtained from severely affected COVID-19 patients (36). In addition to type I IFNs, type II IFN (IFN- $\gamma$ ) which is mainly secreted by $\mathrm{T}$ cells and natural killer cells was also increased in the serum of COVID-19 patients (37). In early SARS-CoV-2 infection increased IFN- $\gamma$ may contribute to antiviral immunity in multiple ways, including the promotion of antigen presentation, inflammatory cell activation and even by directly stimulating the expression of multiple ISGs (38). As the disease progresses however, the viral infection may destroy $\mathrm{T}$-cells and reduce the production of IFN- $\gamma$.

\section{DELAYED IFN RESPONSES IN SARS-COV-2 INFECTION}

Like SARS-CoV, SARS-CoV-2 is also highly sensitive to IFNs in vitro $(35,39)$. In a hamster infection model, intranasal IFN I effectively inhibited SARS-CoV-2 replication and transmission (33). In a phase 2 COVID-19 trial, a combination including IFN$\beta 1 \mathrm{~b}$ effectively alleviated symptoms and shortened the duration of viral shedding, indicating the critical role of IFNs during SARSCoV-2 infection (40). Aging and underlying diseases have a potentially negative impact upon IFN production (41-43). Consistent with this, in multiple retrospective cohort studies there have been higher fatalities in elderly patients with severe COVID-19 $(2,3)$. Similarly, in macaques pulmonary injury was more prominent in an aged group than in a group of young adults (41).

Genetic mutations (TLR3-, TLR7- and IRF7-dependent) and neutralizing auto-antibodies (Abs) that influence type I interferon signaling were shown in severe COVID-19 patients $(11,12,44)$. All these findings underscore the importance of IFNs for protection against SARS-CoV-2. During early SARS-CoV-2 infection however, the host type I IFN response can evidently be low and insufficient, which may be partly caused by immune escape mechanisms of viruses. In a longitudinal follow-up study including 32 COVID-19 patients and 16 influenza-associated pneumonia patients who had similar clinical characteristics to the COVID-19 patients, SARS-CoV-2, but not influenza virus, could trigger an untuned immune response that presented as suppressed and delayed IFN responses and a persistent inflammatory response (45). Delayed type I IFN signaling not only provides a key window for viral replication but could induce tissue damage as observed in SARS-CoV infection $(35,46)$.

\section{Viral Proteins of SARS-CoV-2 Inhibit Type I IFN Secretion}

Four non-structural proteins of SARS-COV-2, including NSP13, NSP15, open reading frame (ORF) 7b, and ORF9b, were identified as interactors of host proteins involved in IFN signaling by affinitypurification mass spectrometry $(23,47)$. At least eight proteins
(NSP1, NSP3, NSP12, NSP13, NSP14, ORF3, ORF6, and M) have also been proven to inhibit IFN- $\beta$ production by gene reporter assays (16). Genetic and clinical data revealed that deletion mutations in NSP1 of SARS-CoV-2 coding region is a variant hotspot that could lead to lower IFN response (48). These studies indicate the existence of a complex regulatory network between SARS-CoV-2 and the host immune system. Viruses tend to downregulate the host immune system by direct disruption of antiviral-associated proteins.

RIG-I activation is dependent on ubiquitination by tripartite motif containing (TRIM)25, of which the interaction could be blocked by NSP5 of SARS-CoV-2 and N protein of SARS-CoV (Figure 2) $(26,49)$. The M protein of SARS-CoV-2 and SARS-CoV prevents the formation of the TRAF3-TBK1/IKK $\in$ complex, thus suppressing IFNs production $(50,51)$. SARS-CoV-2 M protein even affects the formation of the RIG-I-MAVS-TRAF3-TBK1 multiprotein complex and subsequent phosphorylation of IFN regulatory factor 3 (IRF3) (51). As well as steric hindrance, viral components also directly target critical adaptors in antiviral immunity. SARSCoV-2 ORF6 inhibits IFN signals by preventing IRF3 nuclear translocation (16). As a key protease of SARS-CoV-2 that regulates viral replication and spread, papain-like protease (PLpro, a part of NSP3) attenuates IFN responses via the cleavage of ISG15 from IRF3 (52). SARS-CoV-2 also affects the host through the translational level. NSP1 binds to $40 \mathrm{~S}$ ribosomal subunits and obstructs host mRNA translation, thus effectively inhibiting RIGI-mediated IFN responses (Figure 2) (53).

Although a large number of regulatory proteins have been identified via high-throughput screening, their underlying mechanisms with respect to relationships with SARS-CoV-2 are poorly understood. Fortunately, there are great similarities in sequence between SARS-CoV-2 and SARS-CoV, and continued comparison may reveal additional useful information regarding regulation. The N7-methylguanosine $(\mathrm{m} 7 \mathrm{G})$ cap is the defining structural feature of eukaryotic mRNA that distinguishes it from viral RNA. SARS-CoV NSP14 is a novel cap N7-methyltransferase that processes the cap structure of viral RNA to mimic host mRNA and evade recognition (54). ORF9b degrades MAVS, as well as TRAF3 and TRAF6, by usurping poly(C)-binding protein 2 and AID4, a gatekeeper and E3 ligase, thus controlling MAVS expression levels (55). As a crucial adaptor of the antiviral signaling pathway, IRF3 is also a key target of multiple SARS proteins including PLpro, N, ORF3b, and ORF6 protein (Figure 2) $(56,57)$.

\section{SARS-CoV-2 Proteins Inhibit the JAK-STAT Pathway}

As a downstream signaling pathway of IFN, JAK-STAT pathway is crucial for type I IFNs triggered ISGs expression and antiviral responses. During viral infection, responder cells produce and secrete type I IFNs which subsequently bind to their receptor IFNAR (IFN- $\alpha / \beta$ receptor) to initiate JAK-STAT signaling cascades (58). Both SARS-CoV-2 and SARS-CoV infection affect JAK-STAT signaling, thus inhibiting host antiviral innate immunity independent of the level of IFNs $(16,49,59-64)$. Up to now, at least four SARS-CoV-2 proteins (NSP5, ORF7a, N, 
ORF6) and three SARS-CoV proteins (ORF3a, NSP1, ORF6) have been proved to directly affect the activation of JAK-STAT pathway by multiple mechanisms including mediating STAT1/2 degradation and suppressing their phosphorylation and nuclear translocation $(16,49,59-64)$. Resultantly, the expression of ISGs reduced, and antiviral effects get impaired.

\section{EXCESSIVE INFLAMMATION CAUSED BY SARS-COV-2}

During SARS-CoV-2 infection, aberrant inflammatory cytokine responses and the induction of a cytokine storm is closely associated with extensive lung damage and disease severity (65). Compared to mild-to-moderate affected patients, in these severe cases higher levels of pro-inflammatory cytokines (including IL-6, IL-10, and TNF- $\alpha$, etc.) are secreted, and their secretion is correlated with a high serum titer of SARS-CoV-2 and an increased risk of death (66-68). The disrupted secretion of proinflammatory and anti-inflammatory cytokines in severely ill patients results in vascular leakage and fluid accumulation, which is the main cause of ARDS (69). Thus, the seriousness of clinical symptoms may be highly correlated with the inflammatory status of COVID-19 patients.

\section{NF-кB-Associated Inflammation}

Abnormal NF- $\kappa \mathrm{B}$ activation is vital for the initiation and progression of multiple inflammatory respiratory diseases and ARDS $(70,71)$. For SARS-CoV, the S, N, and E proteins as well as ORF3 and ORF8 can activate NF- $\mathrm{KB}$ signaling, leading to the secretion of proinflammatory cytokines (72-75). During SARSCoV-2 infection, two non-structural proteins, NSP13 and ORF9c interact with NF- $\mathrm{KB}$ signaling proteins (TLE1, TLE3, TLE5, NLRX1, F2RL1, and NDFIP2), suggesting that SARS-CoV-2 can regulate the $N F-\kappa B$ signaling pathway (23). The vasoconstrictor angiotensin II (AngII) is also a key factor involved in the pro-inflammatory responses. As the substrate of ACE2, AngII overexpresses after S protein-induced ACE2 internalization (76). After binding with angiotensin receptor 1 (AT1R), AngII initiates numerous kinase activations that result in subsequent inflammatory factor production (76).

\section{NLRP3 Inflammasome-Associated Inflammation}

Higher numbers of NLRP3 and ASC puncta have been observed in COVID-19 patients, and IL-18 and Caspase-1 p20 levels are correlated with disease severity and clinical outcome (77). Specifically, ion fluxes, protein aggregates, and reactive oxygen species (ROS) are all activators of the NLRP3 inflammasome, which can be induced by viral replication and proliferation (30). For SARS-CoV, the E protein activates the NLRP3 inflammasome by forming an ion channel in host ERGIC/ Golgi membranes, and inducing $\mathrm{Ca}^{2+}$ ionic fluxes (78). Similarly, SARS-CoV 3a induces $\mathrm{K}^{+}$efflux and mitochondrial ROS via ion channel activity (31). ORF8b activates the NLRP3 inflammasome by forming an insoluble complex, as well as direct binding with NLRP3 (79). The E protein, with its unique domain containing three macrodomains $(\mathrm{N}, \mathrm{M}$, and $\mathrm{C})$, promotes the production of several cytokines, including IL-1 $\beta$, TNF- $\alpha$, IL-6, CXCL10, and C-C motif chemokine ligand (CCL)5, in a NLRP3dependent manner $(78,80)$. Such positive feedback loop induced by a pro-inflammatory cytokine eventually results in ARDS, which is a primary contributor to the development of SARSCoV-induced pulmonary inflammation $(30,81)$. Moreover, activation of the inflammasome can consequently induce cellular pyroptosis and further aggravate the inflammatory process, leading to extensive tissue inflammation and damage (30). Thus, the NLRP3 inflammasome plays a key role in ARDS and cytokine release syndrome. With the discovery of regulatory proteins for SARS-CoV-2, thorough studies will be conducted to determine the mechanisms governing inflammasome activation.

\section{POTENTIAL THERAPEUTIC TARGETS BASED ON THE VIRUS-HOST INTERACTION}

COVID-19 has rapidly caused a worldwide health crisis, partly because SARS-CoV-2 infects people regardless of age, sex, and race, and no specific antiviral drugs are currently available. Given this situation, effective and specific drugs need to be developed urgently. Innate immune responses in COVID-19 patients can be divided into two phases-early phase (inhibited antiviral innate immunity and low levels of IFNs) and late phase (amplified innate immunity and high levels of IFNs and proinflammatory cytokines), and treatment needs to be administered carefully. Serum IFNs and viral loads need to be detected to determine the suitable timing of treatment administration.

During the early phase, emphasis could be put on inducing IFNs and improving antiviral immunity. In a phase 2 trial for the treatment of SARS-CoV-2 infection, patients receiving SNG001 (nebulized IFN-B1a) exhibited greater improvement and more rapid recovery (82). This phenomenon indicated that local administration of IFN might have different significance from systemic administration. The location, time and duration of IFN exposure may be the key parameters to determine the outcome of viral infection. It also suggested that there may be a substantially greater window (more than 7 days) for beneficial IFN I treatment than initially thought (82). Notably however, in some patients who have neutralizing auto-antibodies against IFNs possibly because of recombination-activating genes (RAG) deficiency, IFNs especially IFN- $\alpha$ administration, is likely to be useless (12). Viral PLpro may cleave proteinaceous post-translational modifications on host proteins as an evasion mechanism against host antiviral immune responses. Given this, GRL-0617 could maintain host IFN responses by targeting SARS-CoV-2 PLpro (52). Similarly, a recent study revealed that famotidine, a histamine receptor-2 blocker, could bind and inhibit the SARS-CoV-2 NSP5 and restore the activation of RIG-I and STAT1 as described above (83). Moreover, in a recent retrospective cohort study, the administration of famotidine in hospitalized COVID-19 patients reduces the risks of severe disease outcomes (84). Currently, the randomized controlled trial 
of famotidine (NCT04370262) is still underway, whose results are awaited with interest (58).

During the late phase, a primary goal of treatment is to maintain inflammation and antiviral immunity at a moderate level. As mentioned above, the activation of NLRP3 inflammasome during COVID-19 could promote excessive release of inflammatory cytokines. To address this, NLRP3 inflammasome inhibitor (Tranilast) in the treatment of COVID-19 is undergoing clinical trial in China (85). Another potential therapeutic agent is resveratrol which has the ability to suppress NF- $\kappa \mathrm{B}$ and inhibit NLRP3 inflammasome activation. Existed studies demonstrated that the administration of resveratrol could inhibit SARS-CoV-2 infection in vitro and ameliorate the pulmonary inflammation and lung injury induced by respiratory viruses in vivo $(86,87)$. In order to relieve the excessive inflammatory responses, targeted drugs are an extremely important strategy in COVID-19 clinical therapy. Currently, the IL-1 receptor antagonist anakinra, monoclonal antibodies against IFN- $\gamma$ and IL- 6 are all candidates for relieving excess inflammatory responses, and their curative effects in COVID-19 patients were highly anticipated $(88,89)$.

\section{CONCLUSION}

In this review, we focused on recent advances in interactions between host immune system and SARS-CoV and SARS-CoV-2,

\section{REFERENCES}

1. Wang D, Hu B, Hu C, Zhu F, Liu X, Zhang J, et al. Clinical Characteristics of 138 Hospitalized Patients With 2019 Novel Coronavirus-Infected Pneumonia in Wuhan, China. JAMA (2020) 323(11):1061-9. doi: 10.1001/ jama.2020.1585

2. Yang X, Yu Y, Xu J, Shu H, Xia J, Liu H, et al. Clinical course and outcomes of critically ill patients with SARS-CoV-2 pneumonia in Wuhan, China: a singlecentered, retrospective, observational study. Lancet Respir Med (2020) 8 (5):475-81. doi: 10.1016/s2213-2600(20)30079-5

3. Zhou F, Yu T, Du R, Fan G, Liu Y, Liu Z, et al. Clinical course and risk factors for mortality of adult inpatients with COVID-19 in Wuhan, China: a retrospective cohort study. Lancet (London England) (2020) 395 (10229):1054-62. doi: 10.1016/s0140-6736(20)30566-3

4. Vabret N, Britton GJ, Gruber C, Hegde S, Kim J, Kuksin M, et al. Immunology of COVID-19: Current State of the Science. Immunity (2020) 52(6):910-41. doi: 10.1016/j.immuni.2020.05.002

5. Vardhana SA, Wolchok JD. The many faces of the anti-COVID immune response. J Exp Med (2020) 217(6):e20200678. doi: 10.1084/ jem.20200678

6. Chen N, Zhou M, Dong X, Qu J, Gong F, Han Y, et al. Epidemiological and clinical characteristics of 99 cases of 2019 novel coronavirus pneumonia in Wuhan, China: a descriptive study. Lancet (London England) (2020) 395 (10223):507-13. doi: 10.1016/s0140-6736(20)30211-7

7. Mehta P, McAuley DF, Brown M, Sanchez E, Tattersall RS, Manson JJ, et al. COVID-19: consider cytokine storm syndromes and immuno suppression. Lancet (2020) 395(10229):1033-4. doi: 10.1016/s0140-6736(20) 30628-0

8. Blanco-Melo D, Nilsson-Payant BE, Liu WC, Uhl S, Hoagland D, Moller R, et al. Imbalanced Host Response to SARS-CoV-2 Drives Development of COVID-19. Cell (2020) 181(5):1036-45 e9. doi: 10.1016/j.cell.2020.04.026 with special emphasis on the imbalance of type I IFNs and inflammation caused by viral infection. At present, IFN therapy was suggested as only beneficial at the early stages of SARS-CoV2 infection, but has little effect on hospitalized patients. Several recent studies have also found that IFN signaling could interfere with lung epithelial repair during recovery from viral infection, thus aggravating the lung injuries $(90,91)$. In COVID-19, the role, dosage and time of IFN in the treatment are worth further examination. Better understanding of the crosstalk between host and SARS-CoV-2 will help to optimize treatment regimens and explore more potential therapeutic targets for COVID-19.

\section{AUTHOR CONTRIBUTIONS}

JZ drafted the manuscript and figures. CZ and WZ edited the manuscript and figures. All authors contributed to the article and approved the submitted version.

\section{FUNDING}

This work was supported by grants from the National Natural Science Foundation of China (81622030, 31870866, 81861130369, and 81901609). WZ is a Newton Advanced Fellow awarded by the Academy of Medical Sciences (NAF007\1003).

9. Hadjadj J, Yatim N, Barnabei L, Corneau A, Boussier J, Smith N, et al Impaired type I interferon activity and inflammatory responses in severe COVID-19 patients. Sci (New York NY) (2020) 369(6504):718-24. doi: 10.1126/science.abc6027

10. Combes A, Courau T, Kuhn N, Hu K, Ray A, Chen W, et al. Global absence and targeting of protective immune states in severe COVID-19. Nature (2021) 591(7848):124-30. doi: 10.1038/s41586-021-03234-7

11. Zhang Q, Bastard P, Liu Z, Le Pen J, Moncada-Velez M, Chen J, et al. Inborn errors of type I IFN immunity in patients with life-threatening COVID-19. Sci (New York NY) (2020) 370(6515):eabd4570. doi: 10.1126/ science.abd4570

12. Bastard P, Rosen LB, Zhang Q, Michailidis E, Hoffmann H-H, Zhang Y, et al. Autoantibodies against type I IFNs in patients with life-threatening COVID19. Sci (New York NY) (2020) 370(6515):eabd4585. doi: 10.1126/ science.abd4585

13. Tay MZ, Poh CM, Renia L, MacAry PA, Ng LFP. The trinity of COVID-19: immunity, inflammation and intervention. Nat Rev Immunol (2020) 20 (6):363-74. doi: 10.1038/s41577-020-0311-8

14. Kim D, Lee JY, Yang JS, Kim JW, Kim VN, Chang H. The Architecture of SARS-CoV-2 Transcriptome. Cell (2020) 181(4):914-21 e10. doi: 10.1016/ j.cell.2020.04.011

15. Yin WC, Mao CY, Luan XD, Shen DD, Shen QY, Su HX, et al. Structural basis for inhibition of the RNA-dependent RNA polymerase from SARSCoV-2 by remdesivir. Science (2020) 368(6498):1499-504. doi: 10.1126/ science.abc1560

16. Lei X, Dong X, Ma R, Wang W, Xiao X, Tian Z, et al. Activation and evasion of type I interferon responses by SARS-CoV-2. Nat Commun (2020) 11(1):3810. doi: 10.1038/s41467-020-17665-9

17. Li M, Li L, Zhang Y, Wang X. Expression of the SARS-CoV-2 cell receptor gene ACE2 in a wide variety of human tissues. Infect Dis Poverty (2020) 9 (1):45. doi: 10.1186/s40249-020-00662-x 
18. Zhao Y, Zhao ZX, Wang YJ, Zhou YQ, Ma Y, Zuo W. Single-Cell RNA Expression Profiling of ACE2, the Receptor of SARS-CoV-2. Am J Respir Crit Care Med (2020) 202(5):756-9. doi: 10.1164/rccm.202001-0179LE

19. Szabo PA, Dogra P, Gray JI, Wells SB, Connors TJ, Weisberg SP, et al. Longitudinal profiling of respiratory and systemic immune responses reveals myeloid cell-driven lung inflammation in severe COVID-19. Immunity (2021) S1074-7613(21)00117-5. doi: 10.1016/j.immuni.2021.03.005

20. Ziegler CGK, Allon SJ, Nyquist SK, Mbano IM, Miao VN, Tzouanas CN, et al. SARS-CoV-2 Receptor ACE2 Is an Interferon-Stimulated Gene in Human Airway Epithelial Cells and Is Detected in Specific Cell Subsets across Tissues. Cell (2020) 181(5):1016-35 e19. doi: 10.1016/j.cell.2020.04.035

21. Mu J, Xu J, Zhang L, Shu T, Wu D, Huang M, et al. SARS-CoV-2-encoded nucleocapsid protein acts as a viral suppressor of RNA interference in cells. Sci China Life Sci (2020) 63(9):1-4. doi: 10.1007/s11427-020-1692-1

22. Fahmi M, Kubota Y, Ito M. Nonstructural proteins NS7b and NS8 are likely to be phylogenetically associated with evolution of 2019-nCoV. Infect Genet Evol (2020) 81:104272. doi: 10.1016/j.meegid.2020.104272

23. Gordon DE, Jang GM, Bouhaddou M, Xu J, Obernier K, White KM, et al. A SARS-CoV-2 protein interaction map reveals targets for drug repurposing. Nature (2020) 583(7816):459-68. doi: 10.1038/s41586-020-2286-9

24. Schoggins J. Interferon-Stimulated Genes: What Do They All Do? Annu Rev Virol (2019) 6(1):567-84. doi: 10.1146/annurev-virology-092818-015756

25. Walls AC, Park YJ, Tortorici MA, Wall A, McGuire AT, Veesler D. Structure, Function, and Antigenicity of the SARS-CoV-2 Spike Glycoprotein. Cell (2020) 181(2):281-92 e6. doi: 10.1016/j.cell.2020.02.058

26. Hu Y, Li W, Gao T, Cui Y, Jin Y, Li P, et al. The Severe Acute Respiratory Syndrome Coronavirus Nucleocapsid Inhibits Type I Interferon Production by Interfering with TRIM25-Mediated RIG-I Ubiquitination. J Virol (2017) 91 (8):e02143-16. doi: 10.1128/JVI.02143-16

27. Zhao X, Chu H, Wong B, Chiu M, Wang D, Li C, et al. Activation of C-Type Lectin Receptor and (RIG)-I-Like Receptors Contributes to Proinflammatory Response in Middle East Respiratory Syndrome Coronavirus-Infected Macrophages. J Infect Dis (2020) 221(4):647-59. doi: 10.1093/infdis/jiz483

28. Carty M, Guy C, Bowie A. Detection of Viral Infections by Innate Immunity. Biochem Pharmacol (2021) 183:114316. doi: 10.1016/j.bcp.2020.114316

29. Imai Y, Kuba K, Neely G, Yaghubian-Malhami R, Perkmann T, van Loo G, et al. Identification of oxidative stress and Toll-like receptor 4 signaling as a key pathway of acute lung injury. Cell (2008) 133(2):235-49. doi: 10.1016/ j.cell.2008.02.043

30. Zhao C, Zhao W. NLRP3 Inflammasome-A Key Player in Antiviral Responses. Front Immunol (2020) 11:211. doi: 10.3389/fimmu.2020.00211

31. Chen IY, Moriyama M, Chang MF, Ichinohe T. Severe Acute Respiratory Syndrome Coronavirus Viroporin 3a Activates the NLRP3 Inflammasome. Front Microbiol (2019) 10:50:50. doi: 10.3389/fmicb.2019.00050

32. Garcia LF. Immune Response, Inflammation, and the Clinical Spectrum of COVID-19. Front Immunol (2020) 11:1441. doi: 10.3389/fimmu.2020.01441

33. Hoagland DA, Møller R, Uhl SA, Oishi K, Frere J, Golynker I, et al. Leveraging the antiviral type-I interferon system as a first line defense against SARS-CoV2 pathogenicity. Immunity (2021) 54(3):557-70.e5. doi: 10.1016/ j.immuni.2021.01.017

34. Cameron MJ, Ran L, Xu L, Danesh A, Bermejo-Martin JF, Cameron CM, et al. Interferon-mediated immunopathological events are associated with atypical innate and adaptive immune responses in patients with severe acute respiratory syndrome. J Virol (2007) 81(16):8692-706. doi: 10.1128/ JVI.00527-07

35. Channappanavar R, Fehr AR, Vijay R, Mack M, Zhao J, Meyerholz DK, et al. Dysregulated Type I Interferon and Inflammatory Monocyte-Macrophage Responses Cause Lethal Pneumonia in SARS-CoV-Infected Mice. Cell Host Microbe (2016) 19(2):181-93. doi: 10.1016/j.chom.2016.01.007

36. Lee J, Park S, Jeong H, Ahn J, Choi S, Lee H, et al. Immunophenotyping of COVID-19 and influenza highlights the role of type I interferons in development of severe COVID-19. Sci Immunol (2020) 5(49):eabd1554. doi: 10.1126/sciimmunol.abd1554

37. Costela-Ruiz V, Illescas-Montes R, Puerta-Puerta J, Ruiz C, MelguizoRodríguez L. SARS-CoV-2 infection: The role of cytokines in COVID-19 disease. Cytokine Growth Factor Rev (2020) 54:62-75. doi: 10.1016/ j.cytogfr.2020.06.001
38. Metz P, Dazert E, Ruggieri A, Mazur J, Kaderali L, Kaul A, et al. Identification of type I and type II interferon-induced effectors controlling hepatitis $\mathrm{C}$ virus replication. Hepatol (Baltimore Md) (2012) 56(6):2082-93. doi: 10.1002/ hep. 25908

39. Mantlo E, Bukreyeva N, Maruyama J, Paessler S, Huang C. Potent Antiviral Activities of Type I Interferons to SARS-CoV-2 Infection. BioRxiv Preprint Server Biol (2020) 2020.04.02.022764. doi: 10.1101/2020.04.02.022764

40. Hung IFN, Lung KC, Tso EYK, Liu R, Chung TWH, Chu MY, et al. Triple combination of interferon beta-1b, lopinavir-ritonavir, and ribavirin in the treatment of patients admitted to hospital with COVID-19: an open-label, randomised, phase 2 trial. Lancet (2020) 395(10238):1695-704. doi: 10.1016/ s0140-6736(20)31042-4

41. Smits SL, de Lang A, van den Brand JM, Leijten LM, van IWF, Eijkemans MJ, et al. Exacerbated innate host response to SARS-CoV in aged non-human primates. PloS Pathog (2010) 6(2):e1000756. doi: 10.1371/journal.ppat.1000756

42. Stout-Delgado HW, Yang X, Walker WE, Tesar BM, Goldstein DR. Aging impairs IFN regulatory factor 7 up-regulation in plasmacytoid dendritic cells during TLR9 activation. J Immunol (2008) 181(10):6747-56. doi: 10.4049/ jimmunol.181.10.6747

43. Smits SL, van den Brand JM, de Lang A, Leijten LM, van Ijcken WF, van Amerongen G, et al. Distinct severe acute respiratory syndrome coronavirusinduced acute lung injury pathways in two different nonhuman primate species. J Virol (2011) 85(9):4234-45. doi: 10.1128/JVI.02395-10

44. van der Made CI, Simons A, Schuurs-Hoeijmakers J, van den Heuvel G, Mantere T, Kersten S, et al. Presence of Genetic Variants Among Young Men With Severe COVID-19. JAMA-J Am Med Assoc (2020) 324(7):663-73. doi: $10.1001 /$ jama.2020.13719

45. Galani I, Rovina N, Lampropoulou V, Triantafyllia V, Manioudaki M, Pavlos $\mathrm{E}$, et al. Untuned antiviral immunity in COVID-19 revealed by temporal type I/III interferon patterns and flu comparison. Nat Immunol (2021) 22(1):3240. doi: $10.1038 / \mathrm{s} 41590-020-00840-\mathrm{x}$

46. Baas T, Taubenberger JK, Chong PY, Chui P, Katze MG. SARS-CoV virushost interactions and comparative etiologies of acute respiratory distress syndrome as determined by transcriptional and cytokine profiling of formalin-fixed paraffin-embedded tissues. J Interferon Cytokine Res (2006) 26(5):309-17. doi: 10.1089/jir.2006.26.309

47. Stukalov A, Girault V, Grass V, Bergant V, Karayel O, Urban C, et al. Multi-level proteomics reveals host-perturbation strategies of SARS-CoV-2 and SARS-CoV. bioRxiv (2020) 2020:6.17.156455. doi: 10.1101/2020. 06.17 .156455

48. Lin J-w, Tang C, Wei H-c, Du B, Chen C, Wang M, et al. Genomic monitoring of SARS-CoV-2 uncovers an Nsp1 deletion variant that modulates type I interferon response. Cell Host Microbe (2021) 29(3):489-502.e8. doi: 10.1016/ j.chom.2021.01.015

49. Wu Y, Ma L, Zhuang Z, Cai S, Zhao Z, Zhou L, et al. Main protease of SARS$\mathrm{CoV}-2$ serves as a bifunctional molecule in restricting type I interferon antiviral signaling. Signal Transduct Targeted Ther (2020) 5(1):221. doi: 10.1038/s41392-020-00332-2

50. Siu KL, Kok KH, Ng MH, Poon VK, Yuen KY, Zheng BJ, et al. Severe acute respiratory syndrome coronavirus $M$ protein inhibits type I interferon production by impeding the formation of TRAF3.TANK.TBK1/ IKKepsilon complex. J Biol Chem (2009) 284(24):16202-9. doi: 10.1074/ jbc.M109.008227

51. Zheng Y, Zhuang M, Han L, Zhang J, Nan M, Zhan P, et al. Severe acute respiratory syndrome coronavirus 2 (SARS-CoV-2) membrane (M) protein inhibits type I and III interferon production by targeting RIG-I/MDA-5 signaling. Signal Transduct Targeted Ther (2020) 5(1):299. doi: 10.1038/ s41392-020-00438-7

52. Shin D, Mukherjee R, Grewe D, Bojkova D, Baek K, Bhattacharya A, et al. Papain-like protease regulates SARS-CoV-2 viral spread and innate immunity. Nature (2020) 587(7835):657-62. doi: 10.1038/s41586020-2601-5

53. Thoms M, Buschauer R, Ameismeier M, Koepke L, Denk T, Hirschenberger $\mathrm{M}$, et al. Structural basis for translational shutdown and immune evasion by the Nsp1 protein of SARS-CoV-2. Science (2020) 369(6508):1249-52. doi: $10.1126 /$ science.abc8665

54. Chen Y, Cai H, Pan J, Xiang N, Tien P, Ahola T, et al. Functional screen reveals SARS coronavirus nonstructural protein nsp14 as a novel cap N7 
methyltransferase. Proc Natl Acad Sci United States America (2009) 106 (9):3484-9. doi: 10.1073/pnas.0808790106

55. Shi CS, Qi HY, Boularan C, Huang NN, Abu-Asab M, Shelhamer JH, et al. SARS-coronavirus open reading frame-9b suppresses innate immunity by targeting mitochondria and the MAVS/TRAF3/TRAF6 signalosome. J Immunol (2014) 193(6):3080-9. doi: 10.4049/jimmunol. 1303196

56. Kopecky-Bromberg SA, Martinez-Sobrido L, Frieman M, Baric RA, Palese P. Severe acute respiratory syndrome coronavirus open reading frame (ORF) $3 b$, ORF 6, and nucleocapsid proteins function as interferon antagonists. J Virol (2007) 81(2):548-57. doi: 10.1128/JVI.01782-06

57. Devaraj SG, Wang N, Chen Z, Chen Z, Tseng M, Barretto N, et al. Regulation of IRF-3-dependent innate immunity by the papain-like protease domain of the severe acute respiratory syndrome coronavirus. J Biol Chem (2007) 282 (44):32208-21. doi: 10.1074/jbc.M704870200

58. Matsuyama T, Kubli S, Yoshinaga S, Pfeffer K, Mak T. An aberrant STAT pathway is central to COVID-19. Cell Death Differ (2020) 27(12):3209-25. doi: 10.1038/s41418-020-00633-7

59. Frieman M, Yount B, Heise M, Kopecky-Bromberg SA, Palese P, Baric RS. Severe acute respiratory syndrome coronavirus ORF6 antagonizes STAT1 function by sequestering nuclear import factors on the rough endoplasmic reticulum/Golgi membrane. J Virol (2007) 81(18):9812-24. doi: 10.1128/ JVI.01012-07

60. Minakshi R, Padhan K, Rani M, Khan N, Ahmad F, Jameel S. The SARS Coronavirus 3a protein causes endoplasmic reticulum stress and induces ligand-independent downregulation of the type 1 interferon receptor. PloS One (2009) 4(12):e8342. doi: 10.1371/journal.pone.0008342

61. Wathelet MG, Orr M, Frieman MB, Baric RS. Severe acute respiratory syndrome coronavirus evades antiviral signaling: role of nsp1 and rational design of an attenuated strain. J Virol (2007) 81(21):11620-33. doi: 10.1128/ JVI.00702-07

62. Miorin L, Kehrer T, Sanchez-Aparicio M, Zhang K, Cohen P, Patel R, et al. SARS-CoV-2 Orf6 hijacks Nup98 to block STAT nuclear import and antagonize interferon signaling. Proc Natl Acad Sci United States America (2020) 117(45):28344-54. doi: 10.1073/pnas.2016650117

63. Cao Z, Xia H, Rajsbaum R, Xia X, Wang H, Shi P. Ubiquitination of SARSCoV-2 ORF7a promotes antagonism of interferon response. Cell Mol Immunol (2021) 18(3):746-8. doi: 10.1038/s41423-020-00603-6

64. Mu J, Fang Y, Yang Q, Shu T, Wang A, Huang M, et al. SARS-CoV-2 N protein antagonizes type I interferon signaling by suppressing phosphorylation and nuclear translocation of STAT1 and STAT2. Cell Discovery (2020) 6:65. doi: 10.1038/s41421-020-00208-3

65. Huang C, Wang Y, Li X, Ren L, Zhao J, Hu Y, et al. Clinical features of patients infected with 2019 novel coronavirus in Wuhan, China. Lancet (London England) (2020) 395(10223):497-506. doi: 10.1016/s0140-6736(20) 30183-5

66. Chen G, Wu D, Guo W, Cao Y, Huang D, Wang H, et al. Clinical and immunological features of severe and moderate coronavirus disease 2019. J Clin Invest (2020) 130(5):2620-9. doi: 10.1172/JCI137244

67. Gao YM, Xu G, Wang B, Liu BC. Cytokine storm syndrome in coronavirus disease 2019: A narrative review. J Intern Med (2020) 289(2):147-61. doi: 10.1111 /joim.13144

68. Grein J, Ohmagari N, Shin D, Diaz G, Asperges E, Castagna A, et al. Compassionate Use of Remdesivir for Patients with Severe Covid-19. N Engl J Med (2020) 382(24):2327-36. doi: 10.1056/NEJMoa2007016

69. Hao D, He L, Qu J, Pan J, Hu B, Zhang J, et al. [A study of pulmonary inflammatory reaction induced by N-protein of SARS-CoV in rat models and effects of glucocorticoids on it]. Zhonghua nei ke za zhi (2005) 44(12):890-3. doi: 10.3760/j.issn:0578-1426.2005.12.004

70. Galani V, Tatsaki E, Bai M, Kitsoulis P, Lekka M, Nakos G, et al. The role of apoptosis in the pathophysiology of Acute Respiratory Distress Syndrome (ARDS): an up-to-date cell-specific review. Pathol Res Pract (2010) 206 (3):145-50. doi: 10.1016/j.prp.2009.12.002

71. Imanifooladi A, Yazdani S, Nourani M. The role of nuclear factor-kappaB in inflammatory lung disease. Inflammation Allergy Drug Targets (2010) 9 (3):197-205. doi: 10.2174/187152810792231904

72. Dosch S, Mahajan S, Collins A. SARS coronavirus spike protein-induced innate immune response occurs via activation of the NF-kappaB pathway in human monocyte macrophages in vitro. Virus Res (2009) 142:19-27. doi: 10.1016/j.virusres.2009.01.005

73. Liao QJ, Ye LB, Timani KA, Zeng YC, She YL, Ye L, et al. Activation of NFkappa B by the full-length nucleocapsid protein of the SARS coronavirus. Acta Biochim Et Biophys Sin (2005) 37(9):607-12. doi: 10.1111/j.17457270.2005.00082.x

74. DeDiego ML, Nieto-Torres JL, Regla-Nava JA, Jimenez-Guardeno JM, Fernandez-Delgado R, Fett C, et al. Inhibition of NF-kappaB-mediated inflammation in severe acute respiratory syndrome coronavirus-infected mice increases survival. J Virol (2014) 88(2):913-24. doi: 10.1128/ JVI.02576-13

75. Kanzawa N, Nishigaki K, Hayashi T, Ishii Y, Furukawa S, Niiro A, et al. Augmentation of chemokine production by severe acute respiratory syndrome coronavirus $3 \mathrm{a} / \mathrm{X} 1$ and $7 \mathrm{a} / \mathrm{X} 4$ proteins through NF-kappaB activation. FEBS Lett (2006) 580(30):6807-12. doi: 10.1016/ j.febslet.2006.11.046

76. Higuchi S, Ohtsu H, Suzuki H, Shirai H, Frank GD, Eguchi S. Angiotensin II signal transduction through the $\mathrm{AT}(\mathrm{I})$ receptor: novel insig hts into mechanisms and pathophysiology. Clin Sci (2007) 112(7-8):417-28. doi: $10.1042 / \operatorname{cs} 20060342$

77. Rodrigues T, de Sá K, Ishimoto A, Becerra A, Oliveira S, Almeida L, et al. Inflammasomes are activated in response to SARS-CoV-2 infection and are associated with COVID-19 severity in patients. J Exp Med (2021) 218(3): e20201707. doi: 10.1084/jem.20201707

78. Nieto-Torres JL, Verdia-Baguena C, Jimenez-Guardeno JM, Regla-Nava JA, Castano-Rodriguez C, Fernandez-Delgado R, et al. Severe acute respiratory syndrome coronavirus $\mathrm{E}$ protein transports calcium ions and activates the NLRP3 inflammasome. Virology (2015) 485:330-9. doi: 10.1016/ j.virol.2015.08.010

79. Shi CS, Nabar NR, Huang NN, Kehrl JH. SARS-Coronavirus Open Reading Frame-8b triggers intracellular stress pathways and activates NLRP3 inflammasomes. Cell Death Discovery (2019) 5:12. doi: 10.1038/s41420-0190181-7

80. Chang YS, Ko BH, Ju JC, Chang HH, Huang SH, Lin CW. SARS Unique Domain (SUD) of Severe Acute Respiratory Syndrome Coronavirus Induces NLRP3 Inflammasome-Dependent CXCL10-Mediated Pulmonary Inflammation. Int J Mol Sci (2020) 21(9):3179. doi: 10.3390/ ijms21093179

81. DeDiego ML, Nieto-Torres JL, Jimenez-Guardeno JM, Regla-Nava JA, Castano-Rodriguez C, Fernandez-Delgado R, et al. Coronavirus virulence genes with main focus on SARS-CoV envelope gene. Virus Res (2014) 194:124-37. doi: 10.1016/j.virusres.2014.07.024

82. Monk P, Marsden R, Tear V, Brookes J, Batten T, Mankowski M, et al. Safety and efficacy of inhaled nebulised interferon beta-1a (SNG001) for treatment of SARS-CoV-2 infection: a randomised, double-blind, placebo-controlled, phase 2 trial. Lancet Respir Med (2020) 9(2):196-206. doi: 10.1016/s22132600(20)30511-7

83. Wu C, Liu Y, Yang Y, Zhang P, Zhong W, Wang Y, et al. Analysis of therapeutic targets for SARS-CoV-2 and discovery of potential drugs by computational methods. Acta Pharm Sin B (2020) 10(5):766-88. doi: 10.1016/ j.apsb.2020.02.008

84. Freedberg D, Conigliaro J, Wang T, Tracey K, Callahan M, Abrams J. Famotidine Use Is Associated With Improved Clinical Outcomes in Hospitalized COVID-19 Patients: A Propensity Score Matched Retrospective Cohort Study. Gastroenterology (2020) 159(3):1129-31.e3. doi: $10.1053 /$ j.gastro.2020.05.053

85. van den Berg D, Te Velde A. Severe COVID-19: NLRP3 Inflammasome Dysregulated. Front Immunol (2020) 11:1580. doi: 10.3389/fimmu.2020.01580

86. Yang M, Wei J, Huang T, Lei L, Shen C, Lai J, et al. Resveratrol inhibits the replication of severe acute respiratory syndrome coronavirus 2 (SARS-CoV-2) in cultured Vero cells. Phytother Res PTR (2020) 35(3):1127-9. doi: 10.1002/ ptr.6916

87. Filardo S, Di Pietro M, Mastromarino P, Sessa R. Therapeutic potential of resveratrol against emerging respiratory viral infections. Pharmacol Ther (2020) 214:107613. doi: 10.1016/j.pharmthera.2020.107613

88. van de Veerdonk FL, Netea MG. Blocking IL-1 to prevent respiratory failure in COVID-19. Crit Care (2020) 24(1):445. doi: 10.1186/s13054-02003166-0 
89. Wiersinga W, Rhodes A, Cheng A, Peacock S, Prescott H. Pathophysiology, Transmission, Diagnosis, and Treatment of Coronavirus Disease 2019 (COVID-19): A Review. JAMA (2020) 324(8):782-93. doi: 10.1001/ jama.2020.12839

90. Major J, Crotta S, Llorian M, McCabe T, Gad H, Priestnall S, et al. Type I and III interferons disrupt lung epithelial repair during recovery from viral infection. Sci (New York NY) (2020) 369(6504):712-7. doi: 10.1126/science.abc2061

91. Broggi A, Ghosh S, Sposito B, Spreafico R, Balzarini F, Lo Cascio A, et al. Type III interferons disrupt the lung epithelial barrier upon viral recognition. Sci (New York NY) (2020) 369(6504):706-12. doi: 10.1126/science.abc3545
Conflict of Interest: The authors declare that the research was conducted in the absence of any commercial or financial relationships that could be construed as a potential conflict of interest.

Copyright (๑) 2021 Zhang, Zhao and Zhao. This is an open-access article distributed under the terms of the Creative Commons Attribution License (CC BY). The use, distribution or reproduction in other forums is permitted, provided the original author(s) and the copyright owner(s) are credited and that the original publication in this journal is cited, in accordance with accepted academic practice. No use, distribution or reproduction is permitted which does not comply with these terms. 